\title{
Development of Impregnated Diamond Bit with Primary and Secondary Abrasives Based on Matrix Weakening Theory
}

\author{
Guofa Zhang ${ }^{1}$, Haidong Jiang ${ }^{2 *}$ \\ ${ }^{1}$ Guizhou Traffic Planning Survey and Design Research Institute Co., Ltd., Guiyang 550081, China \\ ${ }^{2}$ Guizhou Institute of Technology, Guiyang 550081, China
}

Corresponding Author Email: 20170783@git.edu.cn

https://doi.org/10.18280/acsm.450310

Received: 21 February 2021

Accepted: 3 May 2021

\section{Keywords:}

primary and secondary abrasives, impregnated diamond bit, matrix weakening theory, drilling efficiency, service life

\begin{abstract}
Along with economic advancement, diamond bit is widely used in mine exploration and engineering geological investigation. To reduce the cost of impregnated diamond bit and improve its drilling efficiency in highly abrasive formation, this paper designs a diamond bit based on matrix weakening theory, and prepares the matrix from high-grade diamond abrasives and $\mathrm{SiC}$ particles. Through theoretical calculation, diamond bits were designed with six different formulas of diamond concentrations and weakened $\mathrm{SiC}$ particle concentrations. The theoretical analysis shows that the weakened $\mathrm{SiC}$ particle concentration fell within $0-50 \%$; the number of diamond particles dropped from 750,115 to 375,150 , saving the diamond cost by $50 \%$. To further explore the life, drilling efficiency, and working mechanism of diamond bit, the apparent form of bit materials was analyzed through field tests, using EPMA-1720 electron probe microanalyzer and GENSIS60 energy spectrometer. The field tests show that: the proposed bit, with $35 \%$ of matrix skeleton and $65 \%$ of bonding metal, improved the drilling efficiency of ordinary impregnated diamond bit by $68 \%$, while reducing the service life by merely $30 \%$. The apparent form analysis shows that: In the diamond bit designed by matrix weakening theory, the weakened $\mathrm{SiC}$ particles could easily fall off the matrix surface, leaving recoverable pits on the surface. The non-smooth form weakens the abrasion resistance of the matrix, reduces the contact area between the crown of the drill bit and the rock surface at the hole bottom, and increases the pressure of the crown on the rock per unit area. The fallen wakened particles participate in the abrasion of the matrix at the hole bottom, improve the grinding ability of the rock powder at hole bottom, and promote the protrusion of new diamond particles in the matrix.
\end{abstract}

\section{INTRODUCTION}

There are three typical features of hard and dense rock formations with weak abrasiveness [1, 2]: (1) the rocks are hard and rich in quartz; (2) the rocks have an overall high strength, due to the great bonding force between fine silicacemented rock-forming minerals (particle size: $0.01-0.20 \mathrm{~mm}$; uniaxial compressive strength: $150 \mathrm{MPa}$ ); (3) the rocks are weakly abrasive.

For hard, dense, and weakly abrasive formations, the existing studies on the drilling tools mainly focus on matrix formula, bit structure, diamond parameters, as well as manufacturing technology and equipment:

(1) Matrix formula

Focusing on the drilling of hard, dense, and weakly abrasive formations, many scholars have recently proposed the design idea of reducing matrix hardness, with the aim to accelerate the abrasion of the drill bit, and reduce the metabolic rate of matrix $[3,4]$. During the research of matrix formula, they tried to add rare earth or non-metallic elements to alter the mechanical properties of the matrix, inhibit segregation, and purify the reaction interface between the diamond and matrix. Rare earth elements like $\mathrm{La}$ and $\mathrm{Ce}$ are very good at performance regulation. The dosage of these elements usually falls between $0.5 \%$ and $1 \%$. Non-metallic additive elements are another hot topic among researchers engaged in matrix formula [5-7]. The addition of non-metal trace elements, e.g., $\mathrm{Si}, \mathrm{B}$ and $\mathrm{P}$, and graphite powder can improve the performance of the matrix material. Specifically, Si has a strong deoxidation ability; B enhances the abrasion resistance of the matrix, and the bonding strength of matrix to diamond. Adding a proper amount of $\mathrm{P}$ and $\mathrm{Si}$ to the matrix can lower the melting point of $\mathrm{Cu}$ alloy, such that the latter can infiltrate the diamond at a low temperature. Pan Bingsuo et al. studied the effect of graphite on matrix performance, and observed that the abrasion resistance of the matrix first increases and then decreases with the growing content of graphite.

(2) Structure of diamond bit

Considering the features of hard, dense, and weakly abrasive formations, the relevant production units have improved and renovated the bit designs based on the conventional design of diamond bit [8-11] (Figure 1). Among them, Prof. Zhang Shaohe at Central South University, and his team $[12,13]$ examined weakly impregnated diamond bit in details, and applied for a number of patents. Atalas Copco developed a drill bit with primary and secondary nozzles, which partly cools the center of the matrix, and reduces the probability of crown grooving [14]. To extend the service life of drill bit, domestic and foreign researchers and research institutes launched detailed research on drill bits with ultrahigh 
matrix. Boart Longyear developed an ultrahigh matrix with multiple layers of nozzles, whose matrix is as high as $25.4 \mathrm{~mm}$ [15]. The bit can drill into the hard and weakly abrasive formation in Sadbury Basin, Canada by $150 \mathrm{~m}$, and work three times as long as conventional drill bit.

(3) Design parameters of diamond

The optimization of diamond parameters is an idea developed for better metabolic rate of diamond, and better rock-breaking efficiency of each diamond particle, during the drilling into hard, dense, and weakly abrasive formations [1618]. In the light of production practices, drill bit manufacturers began to design diamond parameters by using more diamond particles to improve the bit quality. That is, diamond parameters are designed with a low grade and high concentration. In the course of drilling, the low-grade diamond is easy to break and fall off, which accelerates the metabolism of diamond, and shortens the service life of the bit. This problem could be solved by properly increasing diamond concentration. The diamond bit thus designed can drill into hard, dense, weakly abrasive formations. But the theoretical supports are still lacking. The metallization of diamond surface is another hotspot in the research of diamond performance. Once the surface is metalized, the matrix will be bonded to the diamond more tightly, which reduces the thermal damage of the diamond, and increases the rockbreaking efficiency of each diamond particle.

(4) Manufacturing technology and equipment

The manufacturing technology directly affects the performance and batch stability of the bit. Researchers at home and abroad have studied the manufacturing technology of drill bit extensively $[19,20]$. In foreign countries, impregnated bits are mostly produced by the impregnation method, which can produce bits of various sizes and complex crowns. Drew Mark Butler designed an automatic production line of impregnated bits, making the production much more efficient. In recent years, cold press molding has been combined with hot press sintering into a popular technology for bit production. The hot press sintering faces several defects:

(1) There are vibration and magnetic field vortex during the sintering process, causing the diamonds in the matrix to displace and dislocate, and to concentrate in local areas.

(2) The existing presses only support one-way pressing. After hot pressing, the matrix has uneven density and abrasion resistance: the two parameters gradually decrease along the pressure direction. This greatly limits the effect of the drill bit The combination between cold press molding and hot press sintering helps to improve the stability and quality of the drill bit.

In recent years, granulation technology has gradually been promoted and recognized among manufacturers of diamond tools. This technology ensures the even distribution of diamonds in the matrix, and increases the utilization rate of diamond and fluidity of powders. It is a necessity for cold press molding and automatic volumetric loading. The current granulation technologies can be divided into scrap type and spray type.

During the production of the drill bit, graphite blocks are often adopted for molding nozzles. Despite the simplicity and practicality of the process, the deformation pressure of the matrix powder is limited by the rigid materials of block nozzles. In the end, the sintering pressure is mainly transmitted to graphite blocks, and then transferred to the graphite bottom mode. As a result, the matrix density becomes low, and the service life of the bit becomes short. To solve the problem,
Jilin University developed a formulation and manufacturing scheme for the nozzle material of the bit. The material softens under sintering temperature, and deforms proportionally with matrix materials. In this way, the matrix is made more uneven and dense, thereby improving the overall performance of the bit.

The protrusion of diamond is very difficult, owing to the low efficiency of drilling, and the weak abrasion of the few fine rock powders. As it penetrates hard, dense, and weakly abrasive formations, ordinary diamond bit is susceptible to slippage, that is, the bit does not move deeper or moves slowly into the rock. Then, the drilling cycle is extended, the exploration cost is increased, and the economic benefit is lowered. Therefore, it is practical to address drilling slippage of the bit in this type of rock formation.
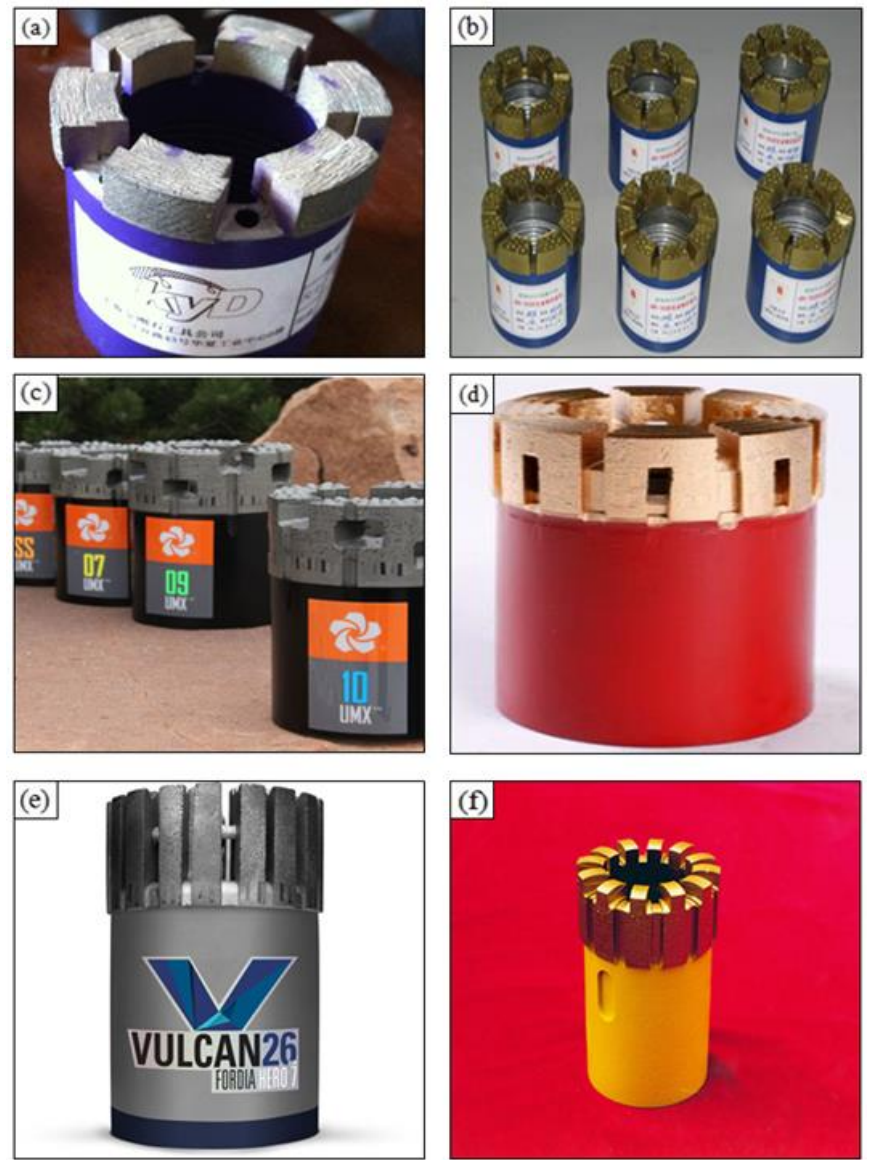

(a) Laser-weld orderly arranged bit; (b) Boart Longyear high matrix bit

(c) Bionic non-smooth diamond bit; (d) Two nozzle diamond bit

(e)Vulcan series diamond bit; (f) Secondary inlaid diamond bit

Figure 1. New diamond bits

Matrix weakening is a process to increase the cutting efficiency of diamond cutting tools. Under the premise of ensuring matrix strength, matrix weakening properly reduces the abrasion resistance of the matrix by an appropriate approach. This paper introduces the matrix weakening theory of diamond cutting tools to the design of impregnated diamond bit, shedding new light on the efficient drilling of impregnated diamond bit in hard, dense, and weakly abrasive rock formations. 


\section{WEAKENING THEORY OF DIAMOND MATRIX}

The weakening theory of diamond matrix mainly covers three aspects: method, surface structure, and material [21, 22].

\subsection{Matrix weakening method}

Studies have shown that different types of diamond tools require different matrix weakening methods, owing to their disparity in design demand. In general, the matrix weakening methods include process control method, additive method, non-smooth surface method, and grain roughening method. The additive method reduces the abrasion resistance of the matrix by adding elements that lowers the matrix toughness, such as silicon, boron, and lanthanum, a rare earth element [5]. The non-smooth surface method achieves the same effect by adding graphite resin synthetic material to form a non-smooth matrix surface. When an impregnated diamond bit drills into hard, dense, and weakly abrasive formations, the weak abrasion of the few fine rock powders will bring difficulty to the protrusion of new diamond particles. This calls for a high self-sharpening ability of the drill bit. Therefore, the additive method was integrated with the non-smooth surface method for bit design. The matrix weakening elements were added to the matrix in the form of hard particles. The bonding force is weak between these particles and the matrix. During the drilling process, the particles could easily fall off from the matrix surface, leaving pits on the surface. The particles remaining at hole bottom work with the rock powders to grind the matrix, enhancing the grinding ability of the powders. In this way, the metabolism of the diamond will pick up speed.

\subsection{Surface structure}

For the conventional impregnated diamond bit, the crown of the cutting tooth is usually designed as a non-smooth toothshaped structure of concentric rings. During the manufacturing, a suitable amount of graphite particles is filled to the bottom of the mold. After sintering, the cutting tooth is sandblasted to create microscopic non-smooth surface of the crown, thereby weakening the abrasion resistance of the matrix. However, it is far from enough to design only one layer of matrix weakening surface on the crown. Once the bit is worn, this layer will vanish, and the crown-rock interface will widen. Then, the bit will witness a decrease in specific pressure and drilling speed. Therefore, the matrix weakening structure can be split into a macro non-renewable structure and micro renewable structure. The former refers to the matrix weakening structure that cannot automatically form after the crown is worn; the latter refers to the non-smooth form that will still appear after the non-smooth form of matrix surface is worn. This paper synthetizes the two matrix weakening structures (Figure 2). The micro renewable structure was realized with matrix weakening particles, and the macro nonrenewable structure was designed as non-smooth tooth-shaped structure of concentric rings.

\subsection{Matrix material}

The performance of bit matrix depends on the formulation of the matrix. Normally, the harder the matrix, the greater the wear resistance, and the longer the service life of the bit [11]. If the formation is soft, the matrix should be relatively hard to suit the small wear of the bit. If the formation is hard, the matrix should be relatively soft to prevent the normal protrusion of the diamond. According to the drillability and grinding features of the test rocks, the matrix formulation for our tests contains $35 \%$ of matrix skeleton and $65 \%$ of bonding metal.

During the drilling into hard, dense, and weakly abrasive formation, the diamond could easily be ground flat. Therefore, the authors selected high-grade diamond abrasives (particle size: $345-455 \mu \mathrm{m}$; compressive strength: $380 \mathrm{~N}$; iMPact strength, TI: $95 \%$ ). The higher the compressive strength and the iMPact toughness of the diamond particles, the smaller the probability for the diamond bit to break in the course of drilling. Therefore, the authors selected strongly abrasive matrix weakening particles, which are weakly bonded with the matrix. The particle size of the selected particles was between 530 and $655 \mu \mathrm{m}$.

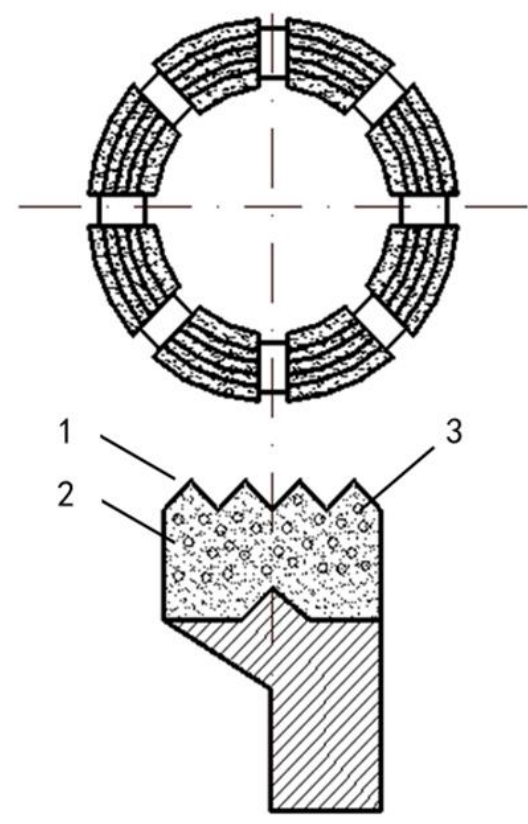

(1) Tooth-shaped structure of concentric rings; (2) Diamond particles; (3) Matrix weakening particles

Figure 2. Surface weakening structure

\section{PARAMETER DESIGN OF MATRIX WEAKENED DIAMOND BIT}

The parameter design of diamond bit mainly involves dimensional parameter design, diamond parameter design, matrix performance parameter design, and waterway system parameter design.

\subsection{Dimensional parameter design}

To meet the general requirements of mining and architectural investigations, the size of diamond bit was set to $\Phi 77 / 49$.

\subsection{Waterway system design}

Eight nozzles were designed for the matrix weakened diamond bit, about $133.3 \%$ of the number for conventional impregnated diamond bit. This is to facilitate the cooling of 
the bit, and the flushing of rock powders, as the matrix weakened impregnated diamond bit drills through hard, dense, and weakly abrasive formations.

\subsection{Diamond parameters}

For the matrix weakened impregnated diamond bit, the diamond parameter design can be broken down into diamond concentration and particle design. Considering the high-grade requirement for matrix weakened impregnated diamond particles, the diamond concentration was set to $100 \%$, and the particle size was set to $355-450 \mu \mathrm{m}$. Due to the negative correlation between diamond concentration and matrix weakening, the number of diamond particles was determined through design calculation.

\subsection{Matrix performance parameters}

The weakening degree is an important parameter in the design of matrix weakened impregnated diamond bit. It refers to the percentage of the matrix weakening particles in matrix volume. The design principle of matrix weakening is to properly reduce the wear resistance of the matrix, under the premise of limiting the damage on the matrix. If the matrix is over weakened, its mechanical properties will be reduced (e.g., bending strength and bonding ability of the diamond), resulting in insecurity of the bit at the hole bottom, abnormal wear, and limited bit life. During the tests, the matrix weakened impregnated diamond bits have the same design parameters as the ordinary impregnated diamond bits. The matrix hardness was set to $\mathrm{HRC} 20$, the weakening degree of the matrix was designed as $0-50 \%(\mathrm{~A} / \mathrm{B} / \mathrm{C} / \mathrm{D} / \mathrm{E} / \mathrm{F})$, and the optimal degree was determined through field tests.

\subsection{Number of diamond particles}

The number of diamond particles is the most important determinant of bit cost. Therefore, this paper attempts to control the bit cost by adjusting the order of magnitudes for the number of diamond particles.

The density of the selected diamond was $3.52 \mathrm{~g} / \mathrm{cm}$. Eight nozzles (size: $13 \times 7 \mathrm{~mm}$ ) were arranged for the $\varphi 77 / 49$ bit. The annular crown area of $\varphi 77 / 49$ diamond bit can be described as:

$$
\mathrm{S}=\pi\left(\mathrm{D}^{2}-\mathrm{d}^{2}\right) / 4=3.14\left(77^{2}-49^{2}\right) / 4=27.70\left(\mathrm{~cm}^{2}\right)
$$

The nozzle area of $\varphi 77 / 49$ diamond bit can be described as:

$$
\mathrm{Ss}=8 \times 13 \times 7=7.28\left(\mathrm{~cm}^{2}\right)
$$

The working area of $\varphi 77 / 49$ diamond bit can be described as:

$$
\mathrm{S}_{\mathrm{g}}=\mathrm{S}-\mathrm{S}_{\mathrm{S}}=20.42\left(\mathrm{~cm}^{2}\right)
$$

The working layer volume of $\varphi 77 / 49$ diamond bit can be described as:

$$
\mathrm{Vg}=\mathrm{Sg} \times \mathrm{H}=24 . .42 \times 0.4=8.168\left(\mathrm{~cm}^{3}\right)
$$

If the concentration of matrix weakening particles is too small, the mechanical performance of the matrix will not be changed obviously. If the concentration is too high, the fallen diamond particles will adhere to the weakening particles.
According to the designed concentration of matrix weakening particles 0 , the test results on the six bits $(10 \%-50 \%)$ are as follows $(10 \%$ for $\mathrm{B})$ :

The $\mathrm{SiC}$ volumes in bits B-F can be respectively expressed as:

$$
\begin{gathered}
\mathrm{V}_{\mathrm{bj}}=\mathrm{Cb} \times \mathrm{Vg}=10 \% \times 8.168=0.817\left(\mathrm{~cm}^{3}\right) \\
\mathrm{V}_{\mathrm{cj}}=\mathrm{Cc} \times \mathrm{Vg}=20 \% \times 8.168=1.634\left(\mathrm{~cm}^{3}\right) \\
\mathrm{V}_{\mathrm{dj}}=\mathrm{Cd} \times \mathrm{Vg}=30 \% \times 8.168=2.450\left(\mathrm{~cm}^{3}\right) \\
\mathrm{V}_{\mathrm{ej}}=\mathrm{Ce} \times \mathrm{Vg}=40 \% \times 8.168=3.267\left(\mathrm{~cm}^{3}\right) \\
\mathrm{V}_{\mathrm{fj}}=\mathrm{Cf} \times \mathrm{Vg}=50 \% \times 8.168=4.084\left(\mathrm{~cm}^{3}\right) \\
\mathrm{V}_{45}=\pi \mathrm{d}^{3} / 6=0.000010889\left(\mathrm{~cm}^{3}\right)
\end{gathered}
$$

The number of diamond particles in bits A-F can be respectively expressed as:

$$
\begin{gathered}
\mathrm{Na}=\mathrm{V}_{\mathrm{aj}} / \mathrm{V}_{45}=750115(\text { each }) \\
\mathrm{Nb}=(1-10 \%) \mathrm{V}_{\mathrm{aj}} / \mathrm{V}_{45}=675270(\text { each }) \\
\mathrm{Nc}=(1-20 \%) \mathrm{V}_{\text {aj }} / \mathrm{V}_{45}=600240(\text { each }) \\
\mathrm{Nd}=(1-30 \%) \mathrm{V}_{\text {aj }} / \mathrm{V}_{45}=525210(\text { each }) \\
\mathrm{Ne}=(1-40 \%) \mathrm{V}_{\text {aj }} / \mathrm{V}_{45}=450180(\text { each }) \\
\mathrm{Nf}=(1-10 \%) \mathrm{V}_{\text {aj }} / \mathrm{V}_{45}=375150(\text { each })
\end{gathered}
$$

The above calculation shows: the greater the concentration of matrix weakening particles, the fewer the diamond particles in the weakened matrix, and the greater the mean pressure on each diamond of the bit crown. Therefore, a high concentration benefits the drilling efficiency. Therefore, the total area concentration of diamonds in the drill bit can be described as:

$$
\mathrm{M}=\mathrm{Mb}+\mathrm{Mbf}
$$

where, $\mathrm{Mb}$ is the diamond concentration; $\mathrm{Mbf}$ is the diamond concentration of matrix weakening design; $\mathrm{M}$ is the total area concentration of diamond.

The above calculation shows that: the higher the concentration of matrix weakening particles, the smaller the area concentration of diamond. In fact, a high area concentration indicates a small spacing between diamond particles. This prevents coarse rock powders to wear the matrix, enhances the breaking effect of diamond on rocks and rock powders, and extends the service life of the bit.

Moreover, the increase of diamond area concentration pushes up the drilling efficiency, but shortens the service life of the bit, resulting in a higher cost of the bit. Hence, it is necessary to strike a balance between the concentration of matrix weakening particles and the area concentration of diamond.

\section{BIT MANUFACTURING TECHNOLOGY}

According to the design requirements, diamond particles, matrix weakening particles, and matrix powders were fully 
mixed, and filled in the assembled graphite mold. Then, the powders were filled in the non-working layers, and the impregnated diamond polycrystalline was placed as per design requirements. Finally, the rigid body of the bit was relocated to the assembled graphite mold for hot press sintering. The hot press sintering includes the following steps:

Put the assembled mold into the induction coil of the medium frequency furnace. Under the heating power of 20 $30 \mathrm{~kW}$, apply an initial pressure was applied after 5-6min of sintering, and elevate the temperature to the holding temperature after $8-9 \mathrm{~min}$ of sintering. Then, apply the full pressure, and maintain the temperature for $5 \mathrm{~min}$. Once the temperature drops to $800^{\circ} \mathrm{C}$, remove the pressure, and relocate the sintering mold of the bit to the incubator or cool it down in the air to room temperature. After removing the mold, conduct machining of the semi-finished bit, and process the waterway system and threads as per design requirements. Table 1 lists the formulation and manufacturing process of the tests.

Table 1. Formulation and manufacturing process parameters

\begin{tabular}{cccccc}
\hline $\begin{array}{c}\text { Bit } \\
\text { number }\end{array}$ & $\begin{array}{c}\text { Granularity } \\
\mu \mathrm{m}\end{array}$ & $\begin{array}{c}\text { SiC particle } \\
\text { concentration }\end{array}$ & $\begin{array}{c}\text { Matrix } \\
\text { hardness }\end{array}$ & $\begin{array}{c}\text { Diamond } \\
\text { concentration }\end{array}$ & $\begin{array}{c}\text { Sintering } \\
\text { pressure }\end{array}$ \\
\hline 1 & 355 & -- & HRC20 & $100 \%$ & $8.0 \mathrm{Mpa}$ \\
2 & 370 & $10 \%$ & HRC20 & $100 \%$ & $800^{\circ} \mathrm{C}$ \\
3 & 385 & $20 \%$ & HRC20 & $100 \%$ & $800^{\circ} \mathrm{C}$ \\
4 & 400 & $30 \%$ & HRC20 & $100 \%$ & $800^{\circ} \mathrm{C}$ \\
5 & 415 & $40 \%$ & HRC20 & $100 \%$ & $800^{\circ} \mathrm{C}$ \\
6 & 430 & $50 \%$ & HRC20 & $3.0 \mathrm{Mpa}$ & $300 \%$ \\
\hline
\end{tabular}

Table 2. Bit test parameters

\begin{tabular}{cccc}
\hline Bit type & Cumulative footage $/ \mathrm{m}$ & Number of round trips & Mean speed $/\left(\mathrm{m} \cdot \mathrm{h}^{-1}\right)$ \\
\hline Ordinary bit & 40.4 & 16 & 0.51 \\
Non-smooth tooth-shaped bit of concentric rings & 35.5 & 12 & 0.64 \\
Matrix weakened bit & 37.2 & 15 & 0.86 \\
\hline
\end{tabular}

Table 3. Bit test results

\begin{tabular}{ccccc}
\hline Bit number & Number of holes/each & Abrasive height $/ \mathrm{mm}$ & Mean speed $/ \mathrm{m} / \mathrm{h}$ & Theoretical life/ $\mathrm{m}$ \\
\hline 1 & 10 & 0.23 & 3.08 & 155 \\
2 & 10 & 0.16 & 3.15 & 146 \\
3 & 10 & 0.13 & 3.38 & 137 \\
4 & 10 & 0.22 & 4.04 & 120 \\
5 & 10 & 0.17 & 4.16 & 112 \\
6 & 10 & 0.12 & 4.27 & 107 \\
\hline
\end{tabular}

\section{FIELD TESTS}
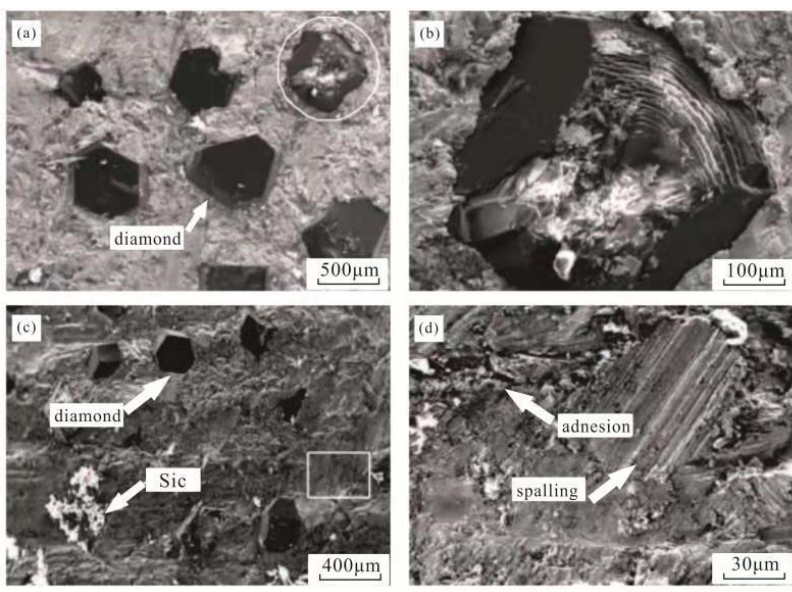

Figure 3. Surface morphology of the matrix

The test site was located in a coal mine of Jiangxi Province. The main strata are as follows:

(1) Quartz rock, hard, dense, poorly abrasive, mean thickness $5-7 \mathrm{~m}$;

(2) Diopside skarn, relatively complete, dense, poorly abrasive, mean thickness $25 \mathrm{~m}$;
(3) Monzonitic granite, relatively complete, embedded with magnetite, poorly abrasive, mean thickness $70 \mathrm{~m}$, discontinuous;

(4) Serpentinous marble, hard, highly silicified, mean thickness $10-15 \mathrm{~m}$.

The drillability of the rocks is Grades 9-11, moderately to strongly abrasive.

The drilling parameters are as follows:

Drilling pressure $95-110 \mathrm{MPa}$; drilling speed 750-850 r/min; pump duty $24 \mathrm{~L} / \mathrm{min}$.

Table 2 presents the bit test parameters. Table 3 shows the drilling results of the test bits.

In addition, the apparent form and micro components of the matrix were analyzed using EPMA-1720 electron probe microanalyzer and GENSIS60 energy spectrometer. The relevant results are shown in Figure 3.

As shown in Tables 2 and 3, the parameter designs of the three bits all suit the lithology of the formation, reaching the expected service life and mechanical speed. The matrix weakened bit improved the drilling efficiency of ordinary impregnated diamond bit by $68 \%$, while reducing the mean service life by a slight margin; this bit improved the drilling efficiency of the non-smooth tooth-shaped bit of concentric rings by $34 \%$. Therefore, the design scheme of the bit is successful for the target formation. The success comes from the following factors: 
(1) The bit formulation and hot press technology are reasonable, and the bit performance is matched with the drilling formation.

(2) The matrix weakening particles being added reduces the abrasion resistance of the matrix, and thus speeds up the metabolism of the diamond in the matrix.

(3) The radially concentric ring structure of the crown brings many free faces, which increases the specific pressure of the crown and improves the rock-breaking efficiency.

\section{CONCLUSIONS}

(1) For the hard, dense, and weakly abrasive formation, an impregnated diamond bit was designed based on the theory of matrix weakening. The size is $\Phi 77 / 49$; the number of nozzles is 8 ; the diamond concentration is $100 \%$; the diamond particle size is $355-450 \mu \mathrm{m}$; the matrix hardness is HRC20; the degree of matrix weakening is $0-50 \%\left(\mathrm{SiC}\right.$ volume is $0.817 \mathrm{~cm}^{3}$ $\left.4.084 \mathrm{~cm}^{3}\right)$.

(2) The matrix weakening theory was combined with impregnated bit design. The matrix weakening particles, coupled with the pitted renewable non-smooth surface, improve the working condition at the hole bottom. Under the premise of ensuring the bit life, this design improves the drilling efficiency of the bit into the hard, dense, and weakly abrasive formation. Compared with the ordinary impregnated diamond bit, the proposed matrix weakened impregnated diamond bit, with $0-50 \%$ of matrix weakening $\mathrm{SiC}$ particles and 375,150 diamond particles (vs. 750,115) improved the drilling efficiency of ordinary impregnated diamond bit by $68 \%$, while reducing the service life by merely $30 \%$.

(3) With the aid of EPMA-1720 electron probe microanalyzer and GENSIS60 energy spectrometer, the surface form and micro components of the matrix were analyzed, and used to verify the matrix weakening theory and derive the damage mechanism of impregnated bit. The results show that the matrix weakening particles roughened the crown. The fallen particles, along with rock powders, filled the crown gaps, and ground the matrix by rolling and slippage. This enhances the abrasion capacity of hole bottom rock powders for the matrix, increases the frictional resistance between bit and rock, and improves the metabolic rate of diamond in the matrix.

\section{REFERENCES}

[1] Zhang, L., Yang, K.H. (2003). Progress of the research on di-amond drilling bits for extra-hard, compact and weak-abrasion rock formation. Diamond \& Abrasives Engineering, 133(1): 30-32.

[2] Jiang, Q.G., Zhang, S.H., Chen, P., Ma, H., Liu, K.W., Zhong, S.J. (2008). Development of new type and high quality impregnated diamond bits. Diamond and Abrasives Engineering, 168(6): 12-16. https://doi.org/10.3969/j.issn.1006-852X.2008.06.004

[3] Xie, L., Chen, L., Huang, X. (2019). Effect of graphite addition on impregnated diamond bit properties. Journal of Superhard Materials, 41(4): 237-246. https://doi.org/10.3103/S106345761904004X

[4] Tan, S., Zhang, W., Duan, L., Pan, B., Rabiei, M., Li, C. (2019). Effects of $\mathrm{MoS}_{2}$ and $\mathrm{WS}_{2}$ on the matrix performance of $\mathrm{WC}$ based impregnated diamond bit.
Tribology International, 131: 174-183. https://doi.org/10.1016/j.triboint.2018.10.038

[5] Zhang, S.Z., Xu, H.Z., Liu, Z.Q., Liu, H.L., Yang, R. (2005). Alloying elements characterization in a Ti-5.6 Al-4.8 Sn-2Zr-1Mo-0.35 Si-1Nd titanium alloy by carbon addition. International Journal of Minerals, Metallurgy and Materials, 12(3): 252-256. https://doi.org/10.2320/jinstmet.69.493

[6] Sreejith, K.P., Sharma, A.K., Kumbhar, S., Kottantharayil, A., Basu, P.K. (2019). An additive-free non-metallic energy efficient industrial texturization process for diamond wire sawn multicrystalline silicon wafers. Solar Energy, 184: 162-172. https://doi.org/10.1016/j.solener.2019.03.062

[7] Ozolin, A.V., Sokolov, E.G., Golius, D.A. (2021). Effect of tungsten nanoparticles on interaction of $\mathrm{Sn}-\mathrm{Cu}-\mathrm{Co}$ metallic matrices with diamond. In IOP Conference Series: Materials Science and Engineering, 1155(1): 012016. $899 X / 1155 / 1 / 012016$

[8] Carpenter, C. (2015). Unconventional polycrystallinediamond-bit design allows significant performance gains Journal of Petroleum Technology, 65(12): 120-122. https://doi.org/10.2118/1213-0120-JPT

[9] Bisht, A., Kumar, R.M., Dasgupta, K., Lahiri, D. (2019). Spatial distribution of nanodiamond and its effect on mechanical behaviour of epoxy based composite using 2D modulus mapping. Mechanics of Materials, 135: 114128. https://doi.org/10.1016/j.mechmat.2019.05.008

[10] Wei, C., Cheng, J., Chen, P., Wei, B., Gao, D., Xu, D. (2019). Facile electroless copper plating on diamond particles without conventional sensitization and activation. Advanced Powder Technology, 30(11): 27512758. https://doi.org/10.1016/j.apt.2019.08.022

[11] Yagi, T., Sakai, T., Kadobayashi, H., Irifune, T. (2020). Review: high pressure generation techniques beyond the limit of conventional diamond anvils. High Pressure Research, $\quad 40(1)$ : 148-161. https://doi.org/10.1080/08957959.2019.1704753

[12] Guo, Q.Q., Wang, J.L., Zhang, S.H. (2015). Effects of matrix weaken particle material on matrix wear resistance of diamond bit based on WC. The Chinese Journal of Nonferrous Metals, 25(9): 2532-2536.

[13] Wang, J.L., Zhang, S.H. (2015). A new diamond bit for extra-hard, compact and nonabrasive rock formation. Journal of Central South University, 22(4): 1456-1462. https://doi.org/10.1007/s11771-015-2663-y

[14] Dawn, M., Geske. (2011). New business technique for atlas copco: company reorganizes, adds fourth business area. Diesel progress: International Edition.

[15] Lockwood, G.T., Zhang, Y., Shen, Y. (2013). U.S. Patent No. 8,347,990. Washington, DC: U.S. Patent and Trademark Office.

[16] Raposo, L.H., Borella, P.S., Ferraz, D.C., Pereira, L.M., Prudente, M.S., Santos-Filho, P.C. (2020). Influence of computer-aided design/computer-aided manufacturing diamond bur wear on marginal misfit of two lithium disilicate ceramic Systems. Operative Dentistry, 45(4): 416-425. https://doi.org/10.2341/19-089-L

[17] Tran, V.T., Thanh, B.T., Long, B.T., Tuan, H.Q., Nguyen, D.T. (2020). Study on the effects of tooth profile design parameters of rotor to performance of vacuum pump. International Journal of Modern Physics B, 34(22n24): 2040141. https://doi.org/10.1088/1674-1056/ab683c 
[18] Gerrer, T., Pomeroy, J., Yang, F., Francis, D., Carroll, J., Loran, B. (2021). Thermal design rules of AlGaN/GaNbased microwave transistors on diamond. IEEE Transactions on Electron Devices, 68(4): 1530-1536. https://doi.org/10.1109/TED.2021.3061319

[19] Gan, W., Jin, X., Wang, X., Chu, H. (2015). Research on the technology of EDM cutting finishing the diamond grinding head. Electromachining \& Mould. https://doi.org/10.3969/j.issn.1009-279X.2015.01.013

[20] Cheng, J., Wu, J., Guo, Z., Gao, C., Yu, T. (2021). Research on a novel fabricating method of diamond grinding tool with defined grain arrangement. The
International Journal of Advanced Manufacturing Technology, pp. 1-21. https://doi.org/10.1007/s00170021-07199-9

[21] Wang, J.L., Zhang, S.H. (2015). Experiment and rock fragmentation mechanism of impregnated diamond bit with weakening matrix. Cent. South Univ., 46(4): 14361441. 7207.2015.04.034

[22] Wang, J., Zhang, S. (2016). Design of impregnated diamond bit based on slipping formation. Earth Science. https://doi.org/10.3799/dqkx.2016.076 